\title{
THE EFFECT OF AMOXICILLIN ON THE SECRETORY STAGE OF AMELOGENESIS IN RATS
}

\author{
Hossam M. Mostafa ${ }^{1 *} M s C$, Fathy I. Shehata ${ }^{2} P h$, Samia S. Omar ${ }^{2} P h D$, Khadiga Y. \\ Kawana $^{2} P h D$
}

\begin{abstract}
INTRODUCTION: Molar-incisor hypomineralization is a developmental enamel defect affecting first permanent molars and incisors. The intake of antibiotics during pregnancy and early childhood has been associated with molar incisor hypomineralization.

OBJECTIVES: Was to determine the effect of amoxicillin on the secretory a stage of amelogenesis histologically and histomorphometrically. MATERIALS AND METHODS: Fourteen pregnant rats were randomly assigned to two groups that received physiological solution (control group), $250 \mathrm{mg} / \mathrm{kg} /$ day amoxicillin (study group). Directly after birth, fourteen pups representing each group received the same treatment with dose equivalent to their body weight then they were euthanized at day 7 birth. The ameloblasts of developing molars were examined histologically and histomorphometrically.

RESULTS: In day 7 after birth, the ameloblasts in control group revealed normal features of amelogenesis while in study group, numerous vacuolar like structures were seen in between secretory ameloblasts.

CONCLUSIONS: Amoxicillin disrupts the normal structure of enamel and impairs the secretion of enamel matrix

KEYWORDS: Ameloblast, amoxicillin, secretory, amelogenesis
\end{abstract}

1- Master of science degree in Oral Biology 2015, Alexandria University.

2- Professor of Oral Biology, Faculty of Dentistry, Alexandria University.

* Corresponding author:

E-mail: hossambio1989@gmail.com

\section{INTRODUCTION}

Molar incisor hypomineralization (MIH) is a challenge for clinical practice (1). It is defined as a developmentally derived dental defect that involves hypomineralization of one or more first permanent molars (1).

MIH differs from enamel hypoplasia, a quantitative enamel defect, since MIH is a qualitative effect identified clinically as demarcated enamel opacities that are also distinguishable from the more diffuse opacities associated with enamel fluorosis (2). MIH affected enamel is consistently soft and chips away easily under masticatory forces from the time the teeth first erupt into the oral cavity, exposing dentin (3).

MIH has been suggested to be caused by various environmental factors that act systemically during pregnancy and childhood, which could act together with genetic variations (4). The main etiological factors of MIH are childhood illnesses, medically compromised children, perinatal factors and medications (5).

Affected teeth exhibit demarcated enamel opacities ranging from white to brown according to severity of the disease. Hypomineralized enamel is soft and porous and it could be easily broken resulting in non-carious cavities (6). Also, the affected teeth are fragile and caries could develop easily in these teeth and they will require extensive restorative treatment. The affected teeth are also very sensitive to hot, cold and mechanical stimuli (7).

The process of enamel formation is called amelogenesis. The formation and mineralization of enamel occurs in stages, beginning at the cusp tips or incisal edges and progressing along the sides of the crown toward the cervical margin. The cells that form the enamel are ameloblasts, which differentiate from the inner enamel epithelium of the enamel organ (6). Ameloblasts exhibit different morphological characteristics according to their functional activity, with distinct phases: presecretory, secretory, transitional, and maturation (7).

During the secretory stage of amelogenesis, ameloblasts initiate enamel matrix secretion and partial mineralization. They develop distal segment of the cells called Tomes' processes which are responsible for the production of the full thickness of enamel and its organization into rod and interred segments (8).

The secretion of enamel matrix starts at the cusp tips and extends in a cervical direction. The initial mineralization of the enamel matrix during secretory stage is about $30 \%$ minerals (9). In the transition from the secretory to the maturation stage, ameloblasts shorten, loose most of the organelles, and about one-fourth of their number undergo apoptosis while in the maturation stage ameloblasts modulate their morphology between ruffle-ended and smooth-ended forms (9).

Ruffle-ended ameloblasts add mineral to the enamel; smooth-ended ameloblasts allow removal of water and degraded matrix proteins. At the end of the maturation stage, almost all of the matrix proteins originally deposited during the secretory stage become degraded and withdrawn from the enamel and replaced by minerals to produce highly mineralized enamel containing about $96 \%$ of its weight minerals (8).

Tooth development is strictly genetically controlled but sensitive to environmental disturbances. In general, systemic factors that disturb the ameloblasts during the secretory stage cause restriction of crystal elongation and result in pathologically thin, or hypoplastic enamel (11).

Also, the interference with initial mineralization during secretory stage results in hypomineralized enamel. However, disturbances during the maturation stage result in 
pathologically soft (hypomaturated)enamel of normal thickness (10).

The ameloblast cells are one of the most sensitive cells to metabolic changes and this is due to its ectodermal origin. There are many factors that could affect amelogenesis and result in MIH. Among these factors are high fever, hypoxia, hypocalcaemia, exposure to antibiotics (3).

Antibiotics are drugs that kill or slow down the growth of bacteria. Some antibiotics are bactericidal as they work through killing bacteria and the other antibiotics are bacteriostatic as they act through stopping bacterial growth (11).

The main classification of antibiotics include BetaLactams (Penicillin and Cephalosporin), Macrolides, Fluoroquinolones, Tetracyclines and Aminoglycosides (12).

Penicillins are generally bactericidal, inhibiting the formation of the bacterial cell wall. Penicillins are used to treat skin infections, dental infections, otitis media, respiratory tract infections, urinary tract infections, and gonorrhea (13).

The macrolides target bacterial ribosomes and prevent protein production and they are mainly bacteriostatic agents. Erythromycin, the prototype of this class, has a spectrum and use similar to penicillin (14).

Cephalosporins have a mechanism of action identical to that of the penicillins. However, the basic chemical structure of the penicillins and cephalosporins differs in other respects, resulting in different spectrum of antibacterial activity (14).

Macrolide antibiotics are used to treat respiratory tract infections (such as pharyngitis, sinusitis, and bronchitis), genital, gastrointestinal tract, and skin infections (14).

It has been suggested that the use of antibiotics is associated with MIH. It was found that amoxicillin, azithromycin and cephalosporins are the most common drugs that affect amelogenesis and may cause MIH (15).

In experimental studies, it has been found that amoxicillin interferes with the initial stages of amelogenesis in the upper first molars of rats exposed pre- and postnatally to the drug (16).

The importance of the secretory and maturation stages of amelogenesis is of great concern for the organization of the whole crown structure and proper tooth functioning and this is one of the causes that evoked the reason for this study. Also, the literature is lacking enough studies on the exact effect of different antibiotics on the secretory and maturation stage of amelogenesis that is why this study was performed. However, the null hypothesis of this study is that no adverse effect of the antibiotics intake during pregnancy or in early childhood will affect the secretory or maturation stage of amelogenesis.

\section{MATERIALS AND METHODS}

This study was approved from the Ethical Committee of Faculty of Dentistry, Alexandria University. The animal housing, breeding and euthanasia were done following the guidelines for the care and use of laboratory animals that is approved by National Research Council (17).

Female rats were mated overnight with males (two females with one male). In the early morning, the male rats were removed from the cages. The presence of sperm in the vaginal smears was considered the first day of pregnancy.
After verification of pregnancy, female rats were divided randomly into two equal groups (7 animals per group).

Group I: rats were received orally sterile physiologic saline to act as a control group.

Group II: rats were received orally $250 \mathrm{mg} / \mathrm{kg}$ amoxicillin (Amoxil, Glaxosmithkline, London, England).

Amoxicillin and physiologic saline were given orally through oral gavage. The treatment was performed starting from day 13 of pregnancy and continued daily till the end of pregnancy. The dose was adjusted according to the body weight of each rat included in the study.

In each group, shortly before birth, the pregnant rats were separated (each in a cage) and after birth two pups were taken from the litter of each mother to get a total number of 14 pups in each group. The mothers did not take any sort of treatment after delivery and each pup received the same treatment of its original group with the dose equivalent to their body weights. The pups were euthanized at day 7 after birth to represent the secretory stage of amelogenesis. The pups were euthanized physically through decapitation.

\section{Histological procedure}

This procedure was done in Oral Biology Department lab, Faculty of Dentistry, Alexandria University. Seven day old rats in each group were euthanized, and the heads were fixed in $10 \%$ neutral buffered formalin solution for 48 hours. After decalcification in 10\% formic acid, containing $0.5 \%$ formaldehyde in $0.1 \mathrm{M}$ sodium phosphate $(\mathrm{pH} 7.2)$, the specimens were dehydrated in ascending concentrations of ethanol, infiltrated in paraffin and finally embedded in paraffin (16).

From each specimen, mesio-distal $5 \mu$ m-thick sections of the upper and lower first molars were obtained and stained with hematoxylin and eosin (16).

\section{Histomorphometric analysis}

The thickness of enamel matrix was measured in the secretory stage of amelogenesis. The measurements were estimated in photos captured using the same magnification with the aid of image analysis system (Image J 1.46o8, java version).

The distance between the amelodentinal junction and ameloblast layer (proximal portion) was measured. In each rat, three specific sections that present a central portion of the tooth germs were selected at least $100 \mu \mathrm{m}$ apart. In each section, three measurements were made from the central portion of the tooth germs. The mean enamel thickness (for the secretory stage) in each rat was estimated, and the mean value and standard deviation per group will be calculated (16).

\section{Statistical analysis}

The statistical analysis of measurements of enamel matrix thickness in the secretory stage of amelogenesis of the two groups was performed using unpaired t test with the aid of SPSS.

\section{RESULTS \\ Histological results \\ I-Control group:}

In this group, the examined developing molars were at late bell stage. Adequate thickness of enamel matrix was observed along the cusp slopes adjacent to the enamel free area at the cusp tips. The ameloblasts appeared as tall columnar polarized cells and their nuclei appeared oval in shape. Their nuclei were shifted towards their proximal 
parts. In the distal part of ameloblasts, well developed Tomes' processes were seen and they interdigitated into the secreted enamel matrix (Figure 1).

Also, in the distal part of ameloblasts, distal terminal bars were seen. It acts as a belt that tightly holds ameloblast together. In addition, tight contacts between ameloblasts and between ameloblasts and stratum intermedium were observed. The secreted enamel matrix was of adequate thickness and in some areas it exhibited the pattern of rod and interrod (Figure 1).

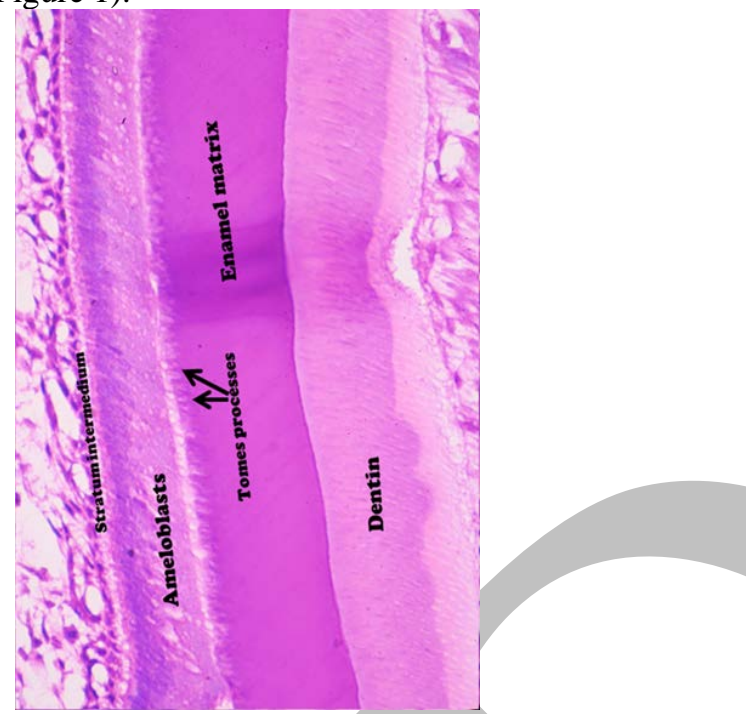

Figure (1): Light micrograph (7 days old rats of control group) showing a continuous layer of tall columnar polarized ameloblasts with distal Tomes' processes that dip into the secreted enamel matrix. The nuclei of ameloblasts are seen in their proximal parts and they are oval in shape. Ameloblasts exhibit close contact between each other and stratum intermedium. $\mathrm{H}$ and $\mathrm{E}$ x 400.

\section{II-Amoxicillin group:}

The examined developing first molars were in the late bell stage. Adequate amount of enamel matrix and dentin were formed along the slopes of the cusps adjacent to the enamel free area that was located at the cusp tip.

Several changes were observed within ameloblasts in different areas of the developing molar. One of these changes was the presence of vacuolar like structures among ameloblasts either in the proximal or distal parts of the cells (Figure 2). Another manifestation was the loss of contact between ameloblasts and between the proximal parts of the ameloblasts and stratum intermedium (Figure 3).

Moreover, in localized areas, the ameloblasts became disorganized and their nuclei lost their polarization and moved to more central or distal parts of the cells. In addition, the distal Tomes' processes were less distinct than their appearance in control group. Regarding the secreted enamel matrix, certain areas exhibited the configuration of rod and interrod while other areas exhibited numerous vacuoles of variable sizes (Figure 4).

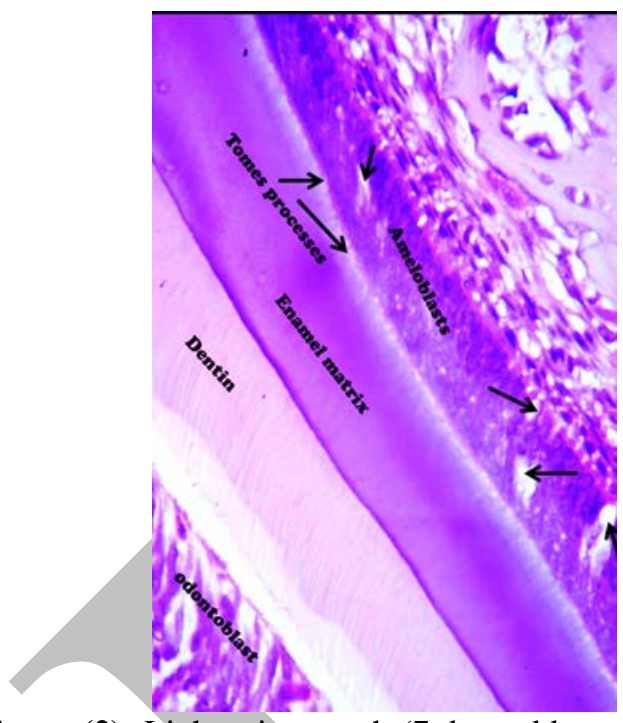

Figure (2): Light micrograph (7 days old rats treated with amoxicillin) showing a single continuous layer of tall columnar polarized ameloblasts with poorly developed Tomes' processes above the secreted enamel matrix. Vacuolar like structures are clearly seen within the ameloblasts (arrows). The secreted enamel matrix is under developed and poorly organized. H and E x 400.

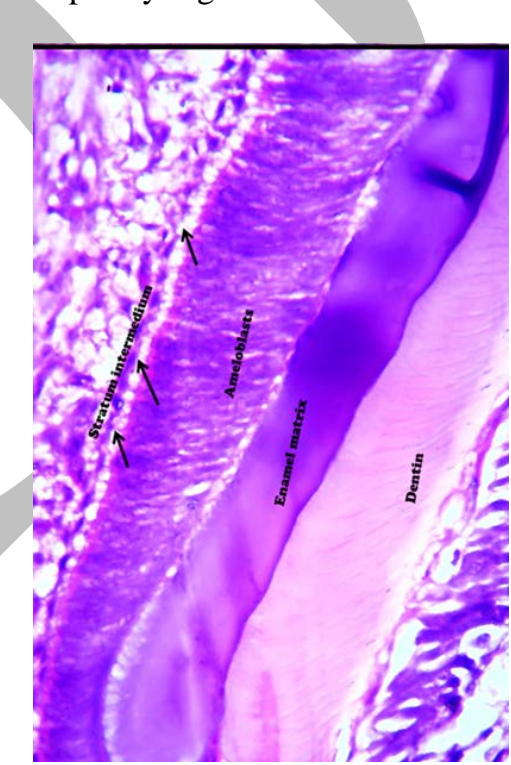

Figure (3): Light micrograph (7 days old rats treated with amoxicillin) of high power view showing disorganized secretory ameloblasts with Tomes' processes above the secreted enamel matrix. Loss of contact between secretory ameloblasts and stratum intermedium is clearly seen (arrows). $\mathrm{H}$ and E x 400. 


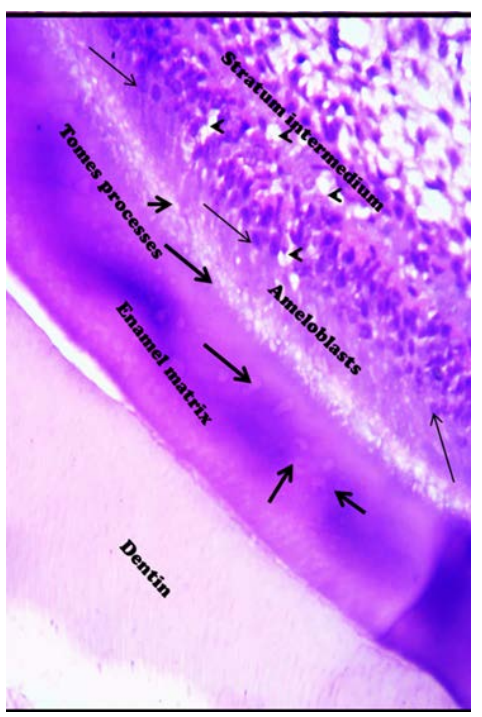

Figure (4): Light micrograph (7 days old rats treated with amoxicillin) showing disorganized secretory ameloblasts with poorly developed Tomes' processes. The nuclei of the ameloblasts lose their polarization and shift toward central or distal parts of the cells (thin arrows). Vacuoles are seen in between ameloblasts (arrow heads). Numerous vacuoles are observed in enamel matrix (thick arrows). $\mathrm{H}$ and $\mathrm{E} \mathrm{X}$ 400.

\section{Results of Histomorphometric analysis (table 1)}

The histomorphometric analysis of the thickness of enamel matrix revealed a significant reduction of enamel matrix thickness in the developing molars in rats treated with amoxicillin $(\mathrm{p}<0.0001)$.

Table (1): Comparison between the thickness of enamel matrix (in pixels) in the secretory stage.

\begin{tabular}{|c|c|c|}
\hline Group & Control group & $\begin{array}{c}\text { Amoxicillin } \\
\text { group }\end{array}$ \\
\hline $\begin{array}{c}\text { Thickness of enamel } \\
\text { matrix (mean } \pm \text { SD) }\end{array}$ & $665.4 \pm 28.2$ & $558.4 \pm 29.7$ \\
\hline P & & $0.0001^{*}$ \\
\hline
\end{tabular}

$\mathrm{p}$ : p value for unpaired t-test between control group and amoxicillin group

*: Statistically significant at $\mathrm{p} \leq 0.05$.

\section{DISCUSSION}

The obtained results from 7 days old rats revealed several changes either within ameloblasts or within the secreted enamel matrix. In review of literature there are strong correlation between the intake of amoxicillin either in pregnancy or in early childhood and the occurrence of enamel hypomineralization.

Laisi et al (18) in their study on 141 school children with MIH found that most of them had received amoxicillin during the first year of life. In another study, Hong et al (19) revealed that the use of amoxicillin from 3 to 6 months resulted in fluorosis of maxillary central incisor. Also, Souza et al (20) on their study in 903 children aged from 612 years found that most of children who received amoxicillin in their first year of life had already affected by MIH.

In the present study, the main finding in amoxicillin group was the presence of vacuolar like structures in between ameloblasts. This finding is in agreement with Souza et el (16) who studied the effect of different doses of amoxicillin on secretory and maturation stage and reported the presence of vacuoles in between ameloblasts in pups in all groups that had received amoxicillin.

Similar results were also found in an in vitro study carried out by Sahlberget al (21), in which mouse germs were exposed to amoxicillin. They found decrease in the enamel thickness and attributed it to the inhibitory effect of amoxicillin on ameloblast differentiation.

Kumazawa et al (22) studied the effect of single intraperitoneal injection of $3.0 \mathrm{~g} / \mathrm{kg}$ body weight amoxicillin on the incisors of rats. Their results revealed that amoxicillin resulted in formation of several areas of interglobular dentin.

Their interpretation was that dentin secretion starts before enamel formation and it is mandatory for the differentiation of ameloblasts, it assumes that amoxicillin could delay the differentiation of ameloblast, and so enamel matrix secretion is disrupted. The reduced quality of enamel matrix in the present study is in accordance with Muñoz et al (23) in who studied the effect of analgesics and antibiotics on the enamel mineralization and demonstrated that amoxicillin reduces the quantity of cyclooxygenase 2 enzyme in the enamel organ and thus affect the quantity and quality of the developing enamel.

In the present study, all changes that occurred within ameloblasts were similar to the changes induced by tetracycline as revealed by Westergraad (24) in his study of the effect tetracycline on secretory ameloblasts revealed that the affected ameloblasts exhibited pyknosis, autophagic vesicles, and the absence of the Tomes' process and the secreted enamel matrix was irregular and reduced in thickness.

To sum up, the chronic exposure to amoxicillin at the time of enamel formation either perinatal or postnatal increases the risk of enamel hypomineralization as amoxicillin interferes with the function of secretory ameloblasts and thus results in poorly developed enamel matrix.

\section{CONCLUSION}

Amoxicillin causes disturbances within secretory ameloblasts and the secreted enamel matrix and thus it reduces the quantity and quality of the developing enamel.

\section{CONFLICT OF INTEREST}

The authors declare that they have no conflicts of interest.

\section{REFERENCES}

1. Weerheijm K, Jälevik B, Alaluusua S. Molar-incisor hypomineralisation. Caries Res. 2001;35:390-1.

2. Alaluusua S. Aetiology of molar-incisor hypomineralisation: a systematic review. Eur Arch Paediatr Dent. 2010;11:53-8.

3. Taylor GD. Molar incisor hypomineralisation. EBD. 2017;18:15.

4. Silva MJ, Scurrah KJ, Craig JM, Manton DJ, Kilpatrick N. Etiology of molar incisor hypomineralization-A systematic review. Community Dent Oral Epidemiol. 2016;44:342-53.

5. Pitiphat W, Luangchaichaweng S, Pungchanchaikul P, Angwaravong O, Chansamak N. Factors associated with molar incisor hypomineralization in $\mathrm{T}$ hai children. Eur $\mathrm{J}$ Oral Sci. 2014;122:265-70. 
6. Hu JC-C, Chun Y-HP, Al Hazzazzi T, Simmer JP. Enamel formation and amelogenesis imperfecta. CTO. 2007;186:78-85.

7. Nanci A, Ahluwalia JP, Pompura JR, Smith CE. Biosynthesis and secretion of enamel proteins in the rat incisor. Anat Rec. 1989;224:277-91.

8. DenBesten P, Li R. Characterization of amelogenin mRNA from secretory-and maturation-stage rat incisor enamel. Arch Oral Biol. 1992;37:1097-100.

9. Smith C. Cellular and chemical events during enamel maturation. Crit Rev Oral Biol Med. 1998;9:128-61.

10. Sabandal MM, Schäfer E. Amelogenesis imperfecta: review of diagnostic findings and treatment concepts. Odont. 2016;104:245-56.

11. Oscáriz JC, Pisabarro AG. Classification and mode of action of membrane-active bacteriocins produced by grampositive bacteria. Int Microbiol. 2001;4:13-9.

12. Kohanski MA, Dwyer DJ, Collins JJ. How antibiotics kill bacteria: from targets to networks. Nat Rev Microbiol. 2010;8:423.

13. Essack SY. The development of $\beta$-lactam antibiotics in response to the evolution of $\beta$-lactamases. Pharm Res. 2001;18:1391-9.

14. Hansen JL, Ippolito JA, Ban N, Nissen P, Moore PB, Steitz TA. The structures of four macrolide antibiotics bound to the large ribosomal subunit. Mol Cell. 2002;10:117-28.

15. Dagan R, Hoberman A, Johnson C, Leibovitz EL, Arguedas A, Rose FV, et al. Bacteriologic and clinical efficacy of high dose amoxicillin/clavulanate in children with acute otitis media. Pediatr Infect Dis J. 2001;20:829-37.
16. De Souza JF, Gramasco M, Jeremias F, Santos-Pinto L, Giovanini AF, Cerri PS, et al. Amoxicillin diminishes the thickness of the enamel matrix that is deposited during the secretory stage in rats. Int J Paediatr Dent. 2016;26:199-210.

17. Council NR. Guide for the care and use of laboratory animals: NAP; 2010.

18. Laisi S, Ess A, Sahlberg C, Arvio P, Lukinmaa P-L, Alaluusua S. Amoxicillin may cause molar incisor hypomineralization. J Dent Res. 2009;88:132-6.

19. Hong L, Levy SM, Warren JJ, Dawson DV, Bergus GR, Wefel JS. Association of amoxicillin use during early childhood with developmental tooth enamel defects. Arch Pediatr Adolesc Med. 2005;159:943-8.

20. Souza J, Costa-Silva C, Jeremias F, Santos-Pinto L, Zuanon ACC, Cordeiro RdCL. Molar incisor hypomineralisation: possible aetiological factors in children from urban and rural areas. Eur Arch Paediatr Dent. 2012;13:164-70.

21. Sahlberg C, Pavlic A, Ess A, Lukinmaa P-L, Salmela E, Alaluusua S. Combined effect of amoxicillin and sodium fluoride on the structure of developing mouse enamel in vitro. Arch Oral Biol. 2013;58:1155-64.

22. Kumazawa K, Sawada T, Yanagisawa T, Shintani S. Effect of single-dose amoxicillin on rat incisor odontogenesis: a morphological study. Clin Oral Invest. 2012;16:835-42.

23. Muñoz CS, Silva AP, Solano F, Castells MT, Vicente A, Ruiz AJO. Effect of antibiotics and NSAIDs on cyclooxygenase-2 in the enamel mineralization. Sci Rep. 2018;8:4132.

24. Westergaard J. Structural changes induced by tetracycline in secretory ameloblasts in young rats. Scand J Dent Res. 1980;88:481

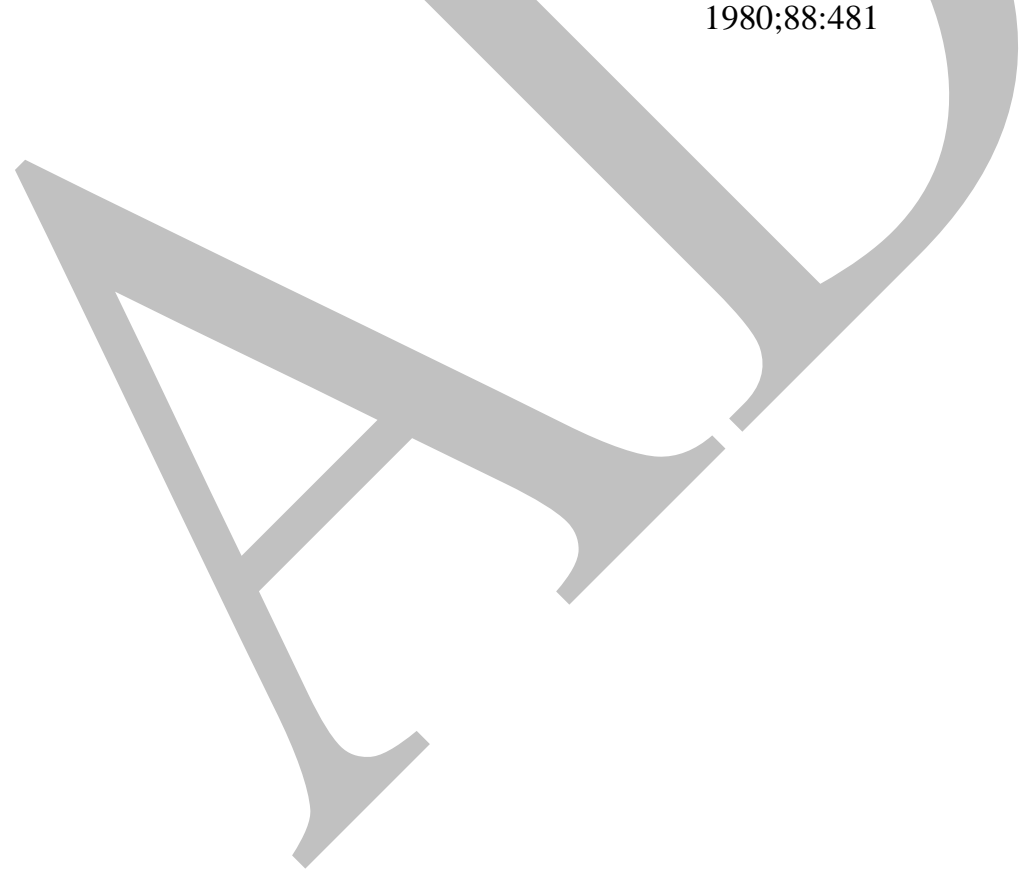

